\title{
Characterisation of strains of Aeromonas spp. by phenotype and whole-cell protein fingerprint
}

\author{
SALLY E. MILLERSHIP and SUSAN V. WANT \\ Department of Bacteriology, Royal Postgraduate Medical School, Hammersmith Hospital, Du Cane Road, \\ London W12 ONN
}

\begin{abstract}
Summary. Sixty-eight isolates of Aeromonas spp. were examined biochemically and their cell proteins were analysed by silver-stained SDS-PAGE. Protein fingerprints did not correlate with phenotype. However, consideration of both phenotype and fingerprint showed clustering of epidemiologically related isolates. There was also evidence that similar strains could be found in infected people and water or other environmental samples.
\end{abstract}

\section{Introduction}

Aeromonas spp. are members of the Vibrionaceae. They are common in fresh surface water ${ }^{1}$ and have long been recognised as occasional human pathogens, especially in soft tissue infections and septicaemia. In the last 10 years there has been increasing interest in their role as a cause of acute gastro-enteritis ${ }^{2}$ although Koch's postulates have not been fulfilled (there is no animal model) and no outbreak attributable to aeromonads has ever been described. The relationship between water and human isolates, and between isolates from different patients is, therefore, of considerable interest. However, investigation of their epidemiology has been hampered by taxonomic confusion, and the difficulty of using conventional techniques such as serology to discriminate between different strains.

In studies during the 1960 s and 1970 s, the motile strains were commonly grouped together as " $A$. hydrophila", as distinct from " $A$. salmonicida", a nonmotile, pigment-producing group which grew poorly or not at all at $37^{\circ} \mathrm{C}$. On the basis of a numerical study of biochemical tests, Popoff and Véron ${ }^{3}$ described two species among the motile strains: $A$. hydrophila, with subspecies anaerogenes and hydrophila, and $A$. sobria. These groups came to be called $A$. caviae, A. hydrophila and $A$. sobria. ${ }^{4}$ This division of isolates appears to be of some biological significance. $A$. caviae is rarely haemolytic but $A$. hydrophila and $A$. sobria usually produce a haemolysin which is also probably a cytotoxin in vitro and an enterotoxin in vivo..$^{5,6}$ Virulence in animal models ${ }^{2}$ and human infections appears to be associated with $A$. hydrophila and $A$. sobria rather than $A$. caviae..$^{7,8}$

It has been shown that each of the three major

Received 27 Oct. 1992; accepted 22 Dec. 1992. phenons include several DNA hybridisation groups (HGs) or genomic species. ${ }^{9}$ Twelve genomic species have so far been described. ${ }^{2}$ Some authors have found a good correlation between phenotype ("phenospecies") and HG, with $A$. hydrophila belonging to HGs 1, 2 and 3, A. caviae to groups 4, 5 and 6 and $A$. sobria to groups $7,8 / 10,9$ and $13 .{ }^{10,11}$ However, this may not always be the case, for Kuijper et al.$^{12}$ found that many strains identified as $A$. hydrophila belonged to $\mathrm{HG} 8$, which is part of the $A$. sobria group. The issue has been further complicated by the description ${ }^{13-15}$ of more phenotypes, some of which correspond to HGs within the original three phenons and some of which are completely new species as determined by DNA hybridisation. ${ }^{16}$ Furthermore, radically different biotypes belong to the same HG. Mesophilic strains are now included in HG 3 with the former members of $A$. salmonicida, and $\mathrm{HG} 8 / 10$ includes most clinical strains of $A$. sobria as $A$. veronii biotype sobria and some biochemically different and independently described isolates known as $A$. veronii biotype veronii. ${ }^{17}$ The aeromonads are clearly a highly heterogeneous group and it is likely that many more phenotypes and hybridisation groups remain to be described.

For epidemiological surveys it is impractical to perform DNA hybridisation on every isolate. A more sensible approach might be to identify isolates as $A$. hydrophila, $A$. sobria or $A$. caviae, ${ }^{4}$ use an electrophoretic fingerprinting technique to further characterise them, and reserve hybridisation for selected isolates.

Whole-cell protein fingerprinting has been used for both taxonomy and differentiation of strains within a species. Bacterial cell preparation is relatively simple and it is particularly suitable for screening large numbers of isolates. The following study was designed to maximise discrimination between strains by using a sensitive silver stain combined with high resolution digital analysis. The results were examined for their 
Table. Scheme used to discriminate recently described phenotypes of Aeromonas spp.

\begin{tabular}{|c|c|c|c|c|c|c|}
\hline Test & $\begin{array}{c}\text { A. veronii* } \\
\text { biotype sobria }\end{array}$ & A. trota & $\begin{array}{l}\text { A. hydrophila } \\
\text { group } \dagger\end{array}$ & $\begin{array}{c}\text { A. veronii } \\
\text { biotype veronii }\end{array}$ & $\begin{array}{l}\text { A. caviae } \\
\text { group } \S\end{array}$ & A. schubertii \\
\hline Aesculin hydrolysis & - & - & + & + & + & - \\
\hline Arabinose fermentation & - & - & + & - & + & - \\
\hline Salicin fermentation & - & - & + & + & + & - \\
\hline Gas from glucose & + & + & + & + & - & - \\
\hline $\mathrm{H}_{2} \mathrm{~S}$ production in GCTF & + & + & + & $?$ & - & $?$ \\
\hline VP test & + & - & + & + & - & - \\
\hline Lysine decarboxylation & + & + & \pm & + & - & + \\
\hline Gluconate & + & - & \pm & $?$ & - & - \\
\hline Elastase production & - & - & $\overline{+}$ & - & - & - \\
\hline Indole production & + & + & + & + & + & - \\
\hline Sucrose fermentation & + & - & + & + & + & - \\
\hline Ampicillin sensitivity & $\mathbf{R}$ & $\mathbf{S}$ & $\mathbf{R}$ & $\mathbf{R}$ & $\mathbf{R}$ & $\mathbf{R}$ \\
\hline Mannitol fermentation & ND & ND & + & + & + & - \\
\hline Cellobiose fermentation & ND & ND & - & \pm & $?$ & - \\
\hline Arginine dihydrolase & ND & ND & + & - & - & + \\
\hline Ornithine decarboxylase & ND & ND & - & + & - & - \\
\hline
\end{tabular}

ND, not done.

* Includes $A$. sobria and $A$. jandaei.

$\dagger$ Includes $A$. salmonicida and $A$. hydrophila.

$\S$ Includes $A$. media, A. eucrenophila and $A$. caviae.

ability to distinguish strains both within and between some currently described phenotypes.

\section{Materials and methods}

\section{Media}

Culture media were supplied by Oxoid except those for fermentation, decarboxylase and dihydrolase tests which were supplied by Southern Group Laboratories. Incubations were overnight in air at $37^{\circ} \mathrm{C}$ except where stated otherwise.

\section{Bacterial strains}

Sixty isolates of Aeromonas spp. from water, food and people in the London area, a colonial variant of one isolate and a replicate of another, and six reference strains-A. caviae ATCC 13136, A. hydrophila ATCC 7965, A. sobria ATCC 9071, A. veronii ATCC 35622, $A$. schubertii ATCC 43700 and $A$. media ATCC 33907 - were examined. Isolates were stored in nutrient broth with glycerol $20 \% \mathrm{v} / \mathrm{v}$ in liquid nitrogen and subcultured on horse-blood agar.

Isolates were identified as aeromonads if they were gram-negative rods, oxidase positive, fermentative, completely resistant to a $150-\mu \mathrm{g}$ disk of the vibriostatic agent $\mathrm{O} / 129$ (Oxoid), and failed to grow in salt $6 \%$ broth yet gave an appropriate biochemical profile for " $A$. hydrophila" in API 20E trays (API system, La Balme Les Grottes, 38390 Montalieu-Vercieu, France). Isolates were then examined as described previously ${ }^{5}$ to differentiate the phenotypes $A$. caviae, $A$. hydrophila and $A$. sobria. ${ }^{4}$ Briefly, examinations were made for: lactose fermentation on MacConkey agar; fermentation of L-arabinose and salicin; pro- duction of gas from glucose; elastase production; hydrogen sulphide production $;^{18}$ decarboxylation of lysine (Moeller's method); hydrolysis of aesculin in aesculin agar; $\beta$-haemolysis on horse-blood agar; growth at $42^{\circ} \mathrm{C}$ on horse-blood agar; the VogesProskauer test by the Barritt method; and oxidation of glucuronic acid. Further differentiation of phenotypes was attempted by inclusion of indole and sucrose tests from the API 20E trays and determinations of sensitivity to ampicillin ${ }^{19}$ defined as a minimal inhibitory concentration (MIC) of $<2 \mathrm{mg} / \mathrm{L}$. Isolates differing from the nearest ideal phenotype by two or more tests were examined further for D-mannitol and cellobiose fermentation in peptone water sugars and formation of ornithine decarboxylase and arginine dihydrolase (Moeller's method).

\section{Electrophoresis and staining of proteins}

Four or five colonies of each isolate were emulsified in $1 \mathrm{ml}$ of distilled water, sodium dodecyl sulphate (SDS) was added to a final concentration of $2 \% \mathrm{w} / \mathrm{v}$, and the samples were boiled for $3 \mathrm{~min}$. The protein concentration was then adjusted with sample buffer ${ }^{20}$ until a 1 in 10 dilution of the sample in water had an $A_{280}$ of 0.1 SD 0.01. Samples were then diluted with an equal volume of sample buffer and stored at $-20^{\circ} \mathrm{C}$ for up to 6 weeks before electrophoresis in polyacrylamide gels. This was performed by the method of Laemmli $^{20}$ at a constant current of $10 \mathrm{~mA}$ when the sample was in the stacking gel (acrylamide $3 \%$ ) and $15 \mathrm{~mA}$ when in the resolving gel (acrylamide $10 \%$ ). The temperature of electrophoresis was controlled at $18 \pm 1^{\circ} \mathrm{C}$ by a thermal recirculation unit to prevent "smile" effects. Gels had 16 or 20 tracks with mol. wt protein markers placed in the exterior lanes and in every third lane. Electrophoresis was continued until 


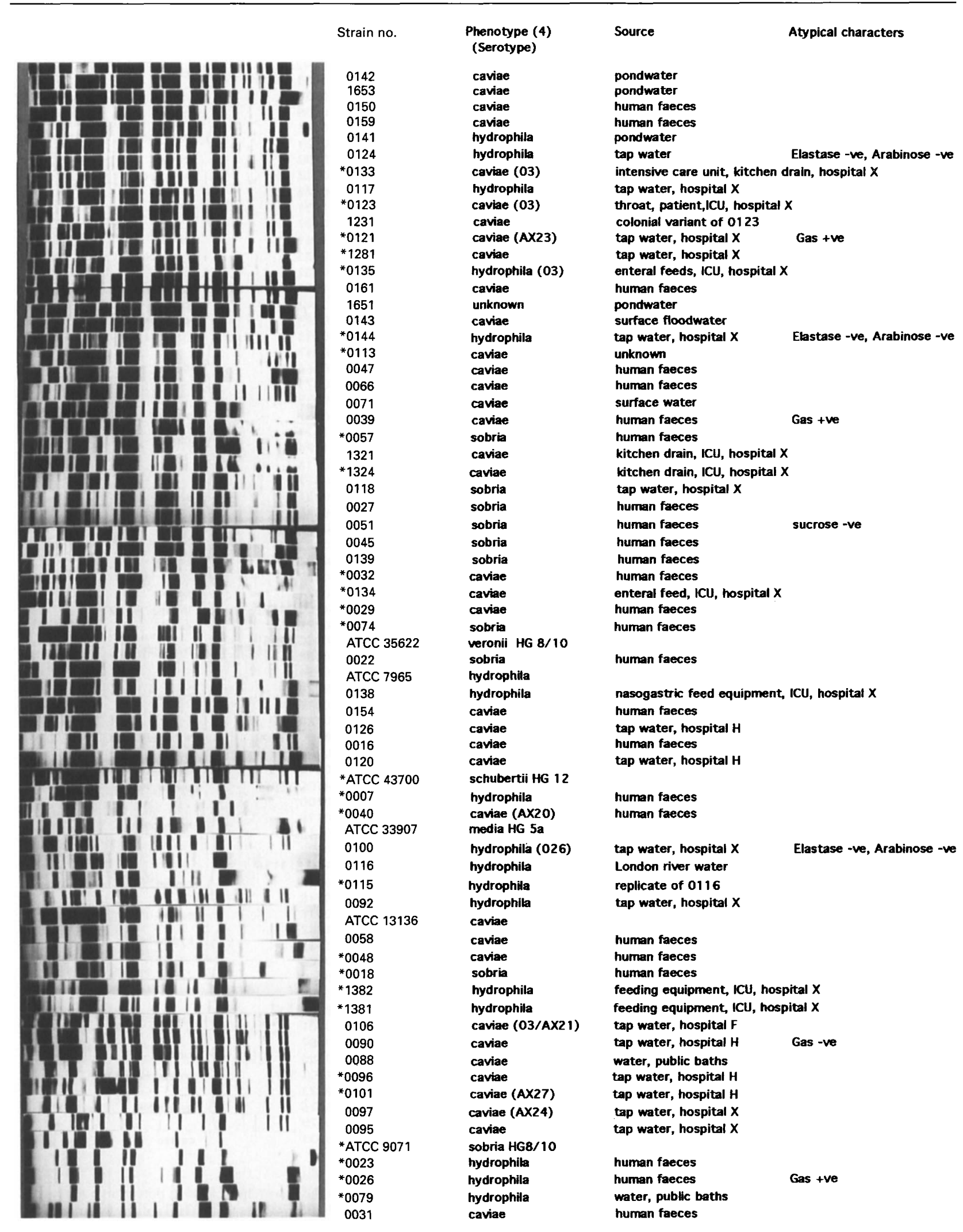

* = Isolates sent to reference laboratory for confirmation of identity and serotyping

Fig. 1. The protein fingerprints, characteristics and source of the 68 Aeromonas isolates studied. Fingerprints were normalised with respect to the mol.-wt markers, high frequency artefact was removed by application of a low pass Fourier filter, and contrast was enhanced before photography from the computer screen.

the bromophenol blue tracking dye was $1 \mathrm{~cm}$ from the bottom. Proteins were then stained with silver, ${ }^{21}$ with some minor modifications to the original technique.
Briefly, gels were fixed overnight in methanol $50 \%$ $\mathrm{v} / \mathrm{v}$, washed in water for $30 \mathrm{~min}$ and soaked in fresh silver diamine solution $\left(0.36 \mathrm{~g} \mathrm{NaOH}, \mathrm{NH}_{4} \mathrm{OH} 35 \%\right.$ 


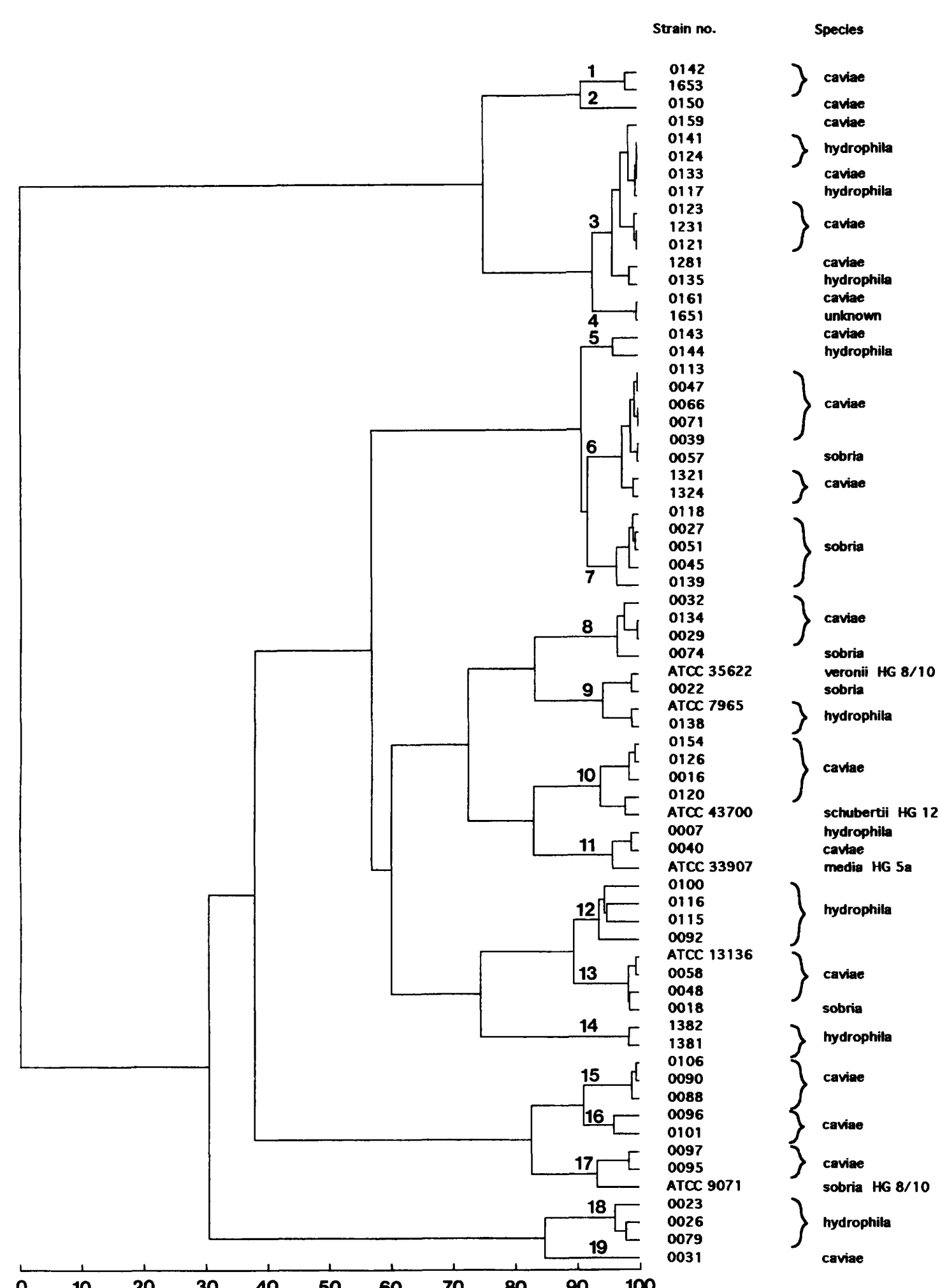

Fig. 2. Cluster analysis of 68 isolates of Aeromonas spp. including replicates. Horizontal axis is the hierarchical level in percentage similarity. Species names are according to Popoff and Véron ${ }^{4}$ except for the named reference strains. The hybridisation group (HG) of the latter is stated where known.

$\mathrm{w} / \mathrm{v} 1.4 \mathrm{ml}$, silver nitrate $20 \% \mathrm{w} / \mathrm{v} 4 \mathrm{ml}$, made up to $100 \mathrm{ml}$ in water) for $15 \mathrm{~min}$ with constant shaking. Gels were then washed twice in water, placed in fresh reducing solution (citric acid $1 \% \mathrm{v} / \mathrm{v} 2.5 \mathrm{ml}$, formaldehyde $36 \% \mathrm{w} / \mathrm{v} 0.26 \mathrm{ml}$ made up to $500 \mathrm{ml}$ with water) and proteins were visualised within 10-20 min. The reaction was stopped with acetic acid $5 \% \mathrm{v} / \mathrm{v}$ and the gel was de-stained in fresh Farmer's solution (sodium thiosulphate $0.6 \mathrm{~g}$, sodium carbonate $0.3 \mathrm{~g}$ and potassium ferricyanide $0.1 \mathrm{~g}$ in $100 \mathrm{ml}$ of water) until all bands had disappeared. Gels were washed until all the yellow Farmer's solution was eluted, fixed in three 1-h washes of methanol $50 \% \mathrm{v} / \mathrm{v}$ and stained as before; the final development of bands occurred in 
6-8 min. Stain development was controlled by inclusion of a control strain of known band pattern. Care was taken to ensure that the final gel dimensions were within $\pm 1 \mathrm{~cm}$ of those before staining began. All isolates were examined in duplicate or triplicate on different gels.

\section{Analysis of gels}

The detailed method has been published elsewhere. ${ }^{22}$ Briefly, gels in a plastic bioassay dish (Nunc) were placed on a high intensity light box (Wardray) and recorded with a charge coupled device (CCD) camera (Model 90, Datacopy Corp., USA) with a $55 \mathrm{~mm}$ Micro-Nikkor lens and Hoya HA50 infra-red filter giving $1728 \times 2240$ picture elements on a 256 point grey scale. Recording was controlled by an IBM PC/AT compatible microcomputer running under MS-DOS with "WIPS" software supplied with the camera. All further image processing was with bespoke software. Gels were viewed in detail and the unwanted margins were deleted with programs compiled by the Microsoft $\mathrm{C}$ compiler v $5 \cdot 1$. They were then transferred from the MS-DOS to a Xenix partition of the hard disk. Tracks were located automatically and a onedimensional density plot was produced by taking an average across the track at each point along its long axis. The plot lengths were normalised to 1024 points by a linear fit of $\log _{e}$ mol. wt on segments. Background density variation was corrected by a Fourier routine to apply a high pass step filter. Density plots were then compared by Fourier routines to calculate the correlation between pairs of plots and derive a similarity coefficient. Cluster analysis of the similarity matrix produced was by a Euclidean distance agglomerative algorithm.

\section{Serotyping}

Twenty-seven isolates were sent to the Division of Enteric Pathogens, Central Public Health Laboratory, Colindale, for confirmation of phenotype and serotyping.

\section{Results}

Thirty-six of the isolates were designated $A$. caviae, 16 as $A$. hydrophila and nine as $A$. sobria. One isolate could not be placed in any recognised group. Isolates were then re-examined as in the table. One sucrosenegative isolate resembling $A$. sobria was found; however, it was also lysine-negative by both API and conventional tests and, therefore, did not correspond to the original description of $A$.jandaei. No isolates of A. veronii, ${ }^{17}$ A. schubertii ${ }^{16}$ or $A$. trota $^{14}$ were identified. Three gas-forming isolates, resembling $A$. caviae but which may be $A$. eucrenophila, were identified. ${ }^{23}$

Only nine $(33 \%)$ of the 27 isolates examined were typable by serology. Three isolates were of serogroup
$\mathrm{O} 3$, and one of $\mathrm{O} 26$ and five, including one reacting with two antisera, belonged to provisional new serogroups. Therefore, serotyping was abandoned.

All isolates yielded a protein fingerprint with $30-40$ bands. The patterns obtained are shown in fig. 1 . They have been digitally processed and contrast enhanced with merging of some closely spaced bands to simplify visual examination.

\section{Reproducibility}

Similarity coefficients of different tracks of the same isolate had a $\beta$ distribution of mean $88 \%$ (SD $8 \%$ ) within gels and $80 \%$ (SD $8 \%$ ) between gels. The greater variation between gels is well known and is usually corrected by careful selection of the limits within which bands in different tracks are considered identical. This is not possible with Fourier correlation; therefore, within-gel similarity coefficients were multiplied by 0.9 so that results of within- and betweenanalysis could be combined. All known replicates fell within the expected cluster identified at the $93 \%$ level in fig. 2.

\section{Cluster analysis}

Five isolates of $A$. sobria clustered together at the $97 \%$ level but otherwise, as is apparent from fig. 1, fingerprints were not related to phenospecies. This was also true for the newer phenospecies. Isolates of very different phenotype could have similar or identical protein fingerprints, whereas some of those of similar phenotype had different fingerprints.

Clusters of isolates from the same or related sources are grouped together (fig. 2). At the $93 \%$ hierarchical level, 19 phenons were defined, of which 10 included two or more phenotypically similar isolates from the same source (nos. 1, 3, 6, 7, 8, 12, 14, 15, 16 and 17). Phenon three was especially complex. It included four environmental isolates of $A$. hydrophila, two of which were from the same hospital, and three phenotypically similar isolates of $A$. caviae, two known to be of the same serotype, also from that hospital.

\section{Discussion}

We analysed 1024 data points along each track to resolve all the visible protein bands. This large number made analysis very sensitive to minor shifts in band positions. For this reason, Fourier correlation, rather than Pearson-product moment correlation, was used to calculate similarity coefficients because the former is less sensitive to some forms of positional shifting. ${ }^{22}$ Reproducibility was acceptable and made fingerprinting highly discriminatory. This method, when considered with the phenotypes of $A$. caviae, $A$. hydrophila and $A$. sobria, permitted the 60 isolates to be divided into 33 groups.

Whole-cell protein fingerprints usually correlate 
well with phenotype. ${ }^{24}$ Therefore, the isolates were examined with regard to the generally accepted phenotypes. ${ }^{4}$ Isolates were then re-examined according to the criteria in the table. Tests in commercial kits are not generally recommended but some were included because they were used in the original descriptions of A. veronii ${ }^{17}$ and $A$. schubertii. ${ }^{16}$ Although separation of all the recognised genotypes of Aeromonas spp. by phenotype has been claimed, ${ }^{11}$ usually the genospecies within the $A$. caviae and $A$. hydrophila phenotypes are not distinguished. ${ }^{2} A$. jandaei can be distinguished from the others by only a few tests, including some in commercial kits; therefore, it was not added to the table.

Whichever phenotyping system was used, there was little relation between protein fingerprint and phenotype, probably because of the increased sensitivity of silver staining for detecting protein bands over that of Coomassie Blue. A previous study of this genus ${ }^{25}$ and species within other genera, ${ }^{26}$ with autoradiography to detect proteins, also showed considerable variation between strains of the same phenospecies. Usually gram-negative species showed variations in band positions between strains, whereas strains of grampositive species showed more variation in relative

\section{References}

1. Burke V, Robinson J, Gracey M, Peterson D, Partridge K. Isolation of Aeromonas hydrophila from a Metropolitan Water supply: seasonal correlation with clinical isolates. Appl Environ Microbiol 1984; 48: 361-366.

2. Janda JM. Recent advances in the study of the taxonomy, pathogenicity, and infectious syndromes associated with the genus Aeromonas. Clin Microbiol Rev 1991; 4: 397-410.

3. Popoff M, Véron M. A taxonomic study of the Aeromonas hydrophila-Aeromonas punctata group. J Gen Microbiol 1976; 94: 11-22.

4. Popoff M. Aeromonas. In: Krieg NR, Holt JG (eds) Bergey's Manual of systematic bacteriology, vol 1. Baltimore, Williams and Wilkins. 1984: 545-548.

5. Barer MR, Millership SE, Tabaqchali S. Relationship of toxin production to species in the genus Aeromonas. $J$ Med Microbiol 1986; 22: 303-309.

6. Potomski J, Burke V, Watson I, Gracey M. Purification of cytotoxic enterotoxin of Aeromonas sobria by use of monoclonal antibodies. $J$ Med Microbiol 1987; 23: 171-177.

7. Janda JM, Reitano M, Bottone EJ. Biotyping of Aeromonas isolates as a correlate to delineating a species-associated disease spectrum. J Clin Microbiol 1984; $19: 44-47$.

8. Millership SE, Barer MR, Tabaqchali S. Toxin production by Aeromonas spp. from different sources. J Med Microbiol $1986 ; 22: 311-314$.

9. Popoff MY, Coynault C, Kiredjian M, Lemelin M. Polynucleotide sequence relatedness among motile Aeromonas species. Curr Microbiol 1981; 5: 109-114.

10. Altwegg M, Steigerwalt AG, Altwegg-Bissig, R, LüthyHottenstein J, Brenner DJ. Biochemical identification of Aeromonas genospecies isolated from humans. $J$ Clin Microbiol 1990; 28: 258-264.

11. Abbott SL, Cheung WKW, Kroske-Bystrom S, Malekzadeh T, Janda JM. Identification of Aeromonas strains to the genospecies level in the clinical laboratory. J Clin Microbiol 1992; 30: $1262-1266$.

12. Kuijper EJ, Steigerwalt AG, Schoenmakers BSCIM, Peeters band densities but fewer differences in band position (unpublished data). This suggests that fingerprints may be a function of cell-wall or outer-membrane proteins, which are known to vary between strains of the same species.

It is also unlikely that fingerprints are related to the DNA hybridisation group because the two reference strains of HG $8 / 10, A$. sobria ${ }^{11}$ and $A$. veronii ${ }^{17}$ are widely separated and the latter is clustered with the reference strain of $A$. hydrophila at the $95 \%$ level.

There is evidence that human and environmental strains may be similar. Phenon 3 included two isolates of $A$. caviae serotype 3 -one from a throat swab and one from the kitchen drain on the same ward. Phenons 7 and 8 included a series of isolates of the same phenotype, some from human sources, including faeces, and some from mains water. It has long been assumed that isolates associated with cases of gastroenteritis are acquired from water or food. All the patients were resident in the same community receiving a common mains water supply, which may be a source of aeromonads. ${ }^{1}$

This work was supported by a grant from the Medical Research Council. We thank Mrs Pearl Allen for her invaluable assistance in typing the manuscript.
MF, Zanen HC, Benner DJ. Phenotypic characterization and DNA relatedness in human fecal isolates of Aeromonas spp. J Clin Microbiol 1989; 27: 132-138.

13. Allen DA, Austin B, Colwell RR. Aeromonas media, a new species isolated from river water. Int J Syst Bact $1983 ; 33$ : 599-604.

14. Carnahan AM, Chakraborty, T, Fanning GR et al. Aeromonas trota sp. nov., an ampicillin-susceptible species isolated from clinical specimens. J Clin Microbiol 1991; 29: 1206-1210.

15. Carnahan A, Fanning GR, Joseph SW. Aeromonas jandaei (formerly genospecies DNA group $9 \mathrm{~A}$. sobria), a new sucrose-negative species isolated from clinical specimens. $J$ Clin Microbiol 1991; 29: 560-564.

16. Hickman-Brenner FW, Fanning GR, Arduino MJ, Brenner DJ, Farmer JJ. Aeromonas schubertii, a new mannitol-negative species found in human clinical specimens. J Clin Microbiol 1988; 26: 1561-1564.

17. Hickman-Brenner FW, MacDonald KL, Steigerwalt AG, Fanning GR, Brenner DJ, Farmer JJ. Aeromonas veronii, a new ornithine decarboxylase-positive species that may cause diarrhea. J Clin Microbiol 1987; 25: 900-906.

18. Veron M, Gasser F. Sur la détection de l'hydrogéne sulfuré produit par certaines entérobactériacées dans les milieux dits de diagnostic rapide. Ann Inst Pasteur 1963; 105: 524-534.

19. Want SV, Millership SE. Effects of incorporating ampicillin, bile salts and carbohydrates in media on the recognition and selection of Aeromonas spp. from faeces. $J \mathrm{Med}$ Microbiol 1990; 32; 49-54.

20. Laemmli UK. Cleavage of structural proteins during the assembly of the head of bacteriophage T4. Nature 1970 ; 227: 680-685.

21. Patel K, Easty DJ, Dunn MJ. Detection of proteins in polyacrylamide gels using an ultrasensitive silver staining technique. In: Walker JM (ed) Methods in molecular biology, vol 3. Clifton, Humana. 1988: 159-168.

22. Millership SE, Ragoonaden K. Automated lanes detection and comparison of bacterial electrophoretic protein fingerprints using fast Fourier transformation. Comput Biomed Res 1992; 25: 392-406. 
23. Schubert RW, Hagazi M. Aeromonas eucrenophila species nova Aeromonas caviae, a later and illegitimate synonym of Aeromonas punctata. Zentralbl Bakteriol Mikrobiol Hyg A 1988; 268: 34-39.

24. Kersters K, De Ley J. Classification and identification of bacteria by electrophoresis. In: Goodfellow M, Beard RG (eds) Microbial classification and identification. London, Academic Press. 1990: 273-298.
25. Stephenson JR, Millership SE, Tabaqchali S. Typing of Aeromonas species by polyacrylamide-gel electrophoresis of radiolabelled cell proteins. J Med Microbiol 1987; 24 : 113-118.

26. Stephenson JR, Crook SJ, Tabaqchali S. New method for typing Staphylococcus aureus resistant to methicillin based on sulphur-35 methionine labelled proteins: its application in an outbreak. $B M J 1986 ; 293$ : 581-584. 